\title{
Prevalence and seasonal trends of malaria at general hospital, Palanpur Banaskantha, Western part of India
}

\author{
Hema S Patel', Gaurav B Modi,"* \\ ${ }^{1}$ Tutor, ${ }^{2}$ Assistant Professor, ${ }^{1}$ Dept. of Pathology, ${ }^{2}$ Dept. of Microbiology, Banas Medical College \& Research Institute, District
} General Hospital Palanpur Banaskantha, Gujarat, India

*Corresponding Author:

Email: gaurav1985bj@gmail.com

\begin{abstract}
Aim: Malaria is one of the known endemic disease in India. Malaria is transmitted by infected female anopheles mosquito vector transmitting mainly two Plasmodial species named P. falciparum and P. vivax. Prevalence of malaria is affected by atmospheric and socioeconomic condition of geographical area. Aim of the study is to know the prevalence of malaria and the seasonal trend of malaria at general hospital Palanpur, Banaskantha in western part of India.

Material and Methods: This study was carried out at Central Laboratory, General Hospital, Palanpur, Banaskantha over period of July 2014 to June 2018. 41660 samples from fever patients were collected. We used Microscopic examination for the diagnosis of malaria by preparing thick and thin smears from these 41660 samples and stained using field stain.

Results: We had collected total 41660 samples of fever patients. Out of 41660 samples, 688 samples were detected positive for malaria. So prevalence of malaria in our hospital was 1.65\%. Prevalence of P. Vivax, P. Falciparum and mixed (infection of P. Falciparum and P. Vivax at a same time) were found $77.90 \%, 21.80 \%$ and $0.30 \%$ respectively. Malaria was seen relatively higher in males and affecting 15-30 years of age group more. Most cases of malaria were found in months of September and October near the end of monsoon and post monsoon season.

Conclusion: From our study we concluded that there was high prevalence of P. vivax than P. Falciparum infection. Maximum numbers of cases were after major rainfall, reported in month of September and October. Morbidity and mortality of malaria must be reduced by strengthening Malaria Surveillance, risk factor assessment during pre and postmonsoon period. Premonsoon preventive actions need strengthening and strict monitoring of all these actions are needed.
\end{abstract}

Keywords: Prevalence, Plasmodium vivax, Plasmodium falciparum, Malaria, Thin and Thick smear, Seasonal trends.

\section{Introduction}

Malaria is a major public health problem in our country in spite of a preventable and treatable disease. ${ }^{1}$ Malaria is caused by Plasmodium parasites. It spreads to people through the bites of infected female Anopheles mosquitoes, known vector for malaria. There are mainly four species that cause human infection i.e. Plasmodium falciparum, Plasmodium vivax, Plasmodium malariae and Plasmodium ovale. Amongst which Plasmodium falciparum and Plasmodium vivax are common in India. As well as Plasmodium falciparum is more fatal than Plasmodium vivax because of its complications. ${ }^{2}$ Factors affecting the spread of malaria are atmospheric conditions that may affect the number and survival of mosquitoes, such as rainfall patterns, temperature, humidity and socioeconomic conditions. In some area, transmission of malaria is seasonal, with the peak during and just after the rainy season. ${ }^{3,4}$ There were 2.5 million cases of malaria in Southeast Asia to the global burden of malaria. Of this, India had reported $76 \%$ of the cases. ${ }^{5}$ Every year 0.7-1.6 million confirmed cases of malaria reported in India and out of these 400-1000 deaths occurred annually. ${ }^{6}$ Now a days it is problem of both rural and urban areas so this study aims to know the prevalence of malaria and the seasonal trend of malaria at general hospital Palanpur, Banaskantha in western part of India.

\section{Material and Methods}

This study was carried out at Central Laboratory, General Hospital, Palanpur, Banaskantha over period a period of 4 years from July 2014 to June 2018. All the fever cases undergone investigations for malarial parasites were included in present study from defined time period. 41660 samples were collected from outdoor or indoor patients. We used Microscopic examination for the diagnosis of malaria by preparing thick and thin smears from these 41660 samples and stained using field stain. Malarial parasites with various forms were identified by thick smear and species identification by thin smear.

\section{Results}

41660 samples for malaria were tested for microscopic examination. 688 samples were positive for plasmodia. So prevalence of malarial parasite was $1.65 \%$. 
Table 1: Year wise positivity rate of different malarial parasite

\begin{tabular}{|l|c|c|c|c|c|}
\hline \multicolumn{1}{|c|}{ Year } & $\begin{array}{c}\text { Total } \\
\text { Slide }\end{array}$ & $\begin{array}{c}\text { Malaria } \\
\text { Slide } \\
\text { Positivity }\end{array}$ & P.vivax & $\begin{array}{c}\text { P. } \\
\text { Falciparum }\end{array}$ & Mixed \\
\hline 2014 (July-December) & 5670 & $84(1.48 \%)$ & $55(65.47 \%)$ & $29(34.53 \%)$ & 0 \\
\hline 2015 & 8462 & $163(1.92 \%)$ & $130(79.75 \%)$ & $31(19.01 \%)$ & $2(1.24 \%)$ \\
\hline 2016 & 11990 & $197(1.64 \%)$ & $150(76.14 \%)$ & $47(23.86 \%)$ & 0 \\
\hline 2017 & 10991 & $214(1.95 \%)$ & $175(81.78 \%)$ & $39(18.22 \%)$ & 0 \\
\hline 2018 (January To June) & 4547 & $30(0.66 \%)$ & $26(86.67 \%)$ & $4(13.33 \%)$ & 0 \\
\hline & 41660 & $688(1.65 \%)$ & $536(77.90 \%)$ & $150(21.80 \%)$ & $2(0.30 \%)$ \\
\hline
\end{tabular}

From Table 1, 536(77.90\%) cases were positive for P.vivax, $150(21.80 \%)$ cases were positive for P.faciparum and $2(0.30 \%)$ cases were positive for mixed (both P.vivax and P.falciparum) infection. In year 2015 and 2017, prevalence of malaria were noted $1.92 \%$ and $1.95 \%$ respectively higher than average prevalence rate due to heavy rainfall and flood situation in Palanpur and Banaskantha district.

Table 2: Month wise positivity rate of malaria species

\begin{tabular}{|l|c|c|c|c|c|}
\hline \multicolumn{1}{|c|}{ Month } & $\begin{array}{c}\text { Total } \\
\text { samples }\end{array}$ & $\begin{array}{c}\text { Total } \\
\text { positive }\end{array}$ & $\begin{array}{c}\text { P. vivax } \\
(\%)\end{array}$ & $\begin{array}{c}\text { P. falciparum } \\
(\%)\end{array}$ & $\begin{array}{c}\text { Mixed } \\
\text { Infection }\end{array}$ \\
\hline January & 2976 & $4(0.13 \%)$ & $4(100 \%)$ & 0 & 0 \\
\hline February & 3734 & $4(0.11 \%)$ & $2(50 \%)$ & $2(50 \%)$ & 0 \\
\hline March & 3260 & $12(0.37 \%)$ & $12(100 \%)$ & 0 & 0 \\
\hline April & 2351 & $25(1.06 \%)$ & $21(84 \%)$ & $4(16 \%)$ & 0 \\
\hline May & 2341 & $44(1.88 \%)$ & $42(95.45 \%)$ & $2(4.55 \%)$ & 0 \\
\hline June & 2195 & $39(1.77 \%)$ & $37(94.87 \%)$ & 0 & $2(5.13 \%)$ \\
\hline July & 3182 & $58(1.82 \%)$ & $47(81.03 \%)$ & $11(18.97 \%)$ & 0 \\
\hline August & 4906 & $95(1.94 \%)$ & $78(82.10 \%)$ & $17(17.90 \%)$ & 0 \\
\hline September & 5695 & $210(3.69 \%)$ & $169(80.47 \%)$ & $41(19.53 \%)$ & 0 \\
\hline October & 4572 & $112(2.45 \%)$ & $76(67.86 \%)$ & $36(32.14 \%)$ & 0 \\
\hline November & 3622 & $64(1.76 \%)$ & $39(60.93 \%)$ & $25(39.07 \%)$ & 0 \\
\hline December & 2826 & $21(0.74 \%)$ & $9(42.85 \%)$ & $12(57.15 \%)$ & 0 \\
\hline & 41660 & $688(1.65 \%)$ & $536(77.90 \%)$ & $150(21.80 \%)$ & $2(0.30 \%)$ \\
\hline
\end{tabular}

Graph 1: Month wise distribution of malaria cases during study period

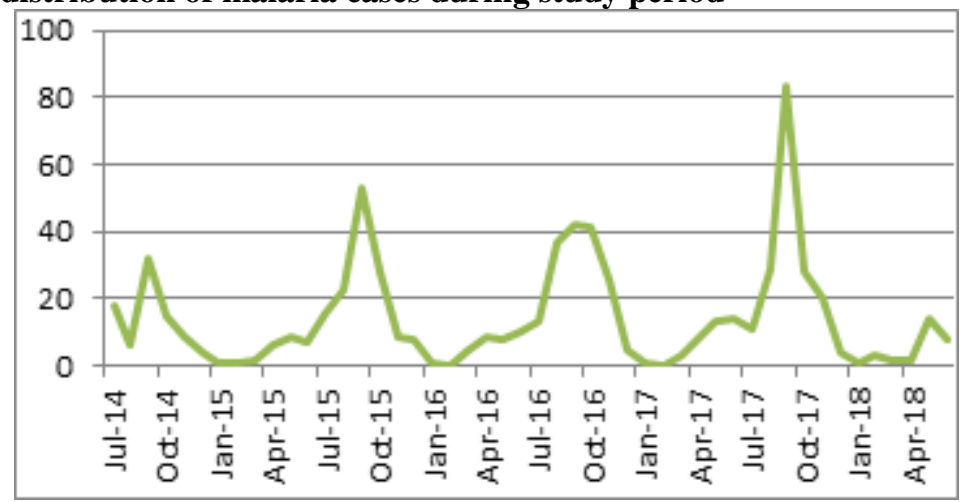

From table no.2 and graph no.1, maximum numbers of malarial cases were noted in September(210), October(112) and August(95) months. Prevalence of malarial parasites in these months were
$3.69 \%, 2.45 \%$ and $1.94 \%$ respectively higher than average prevalence rate. Lowest prevalence rate of malaria were found in February $(0.11 \%)$ and January $(0.13 \%)$ months.

Table 3: Age and sex wise distribution of malaria case

\begin{tabular}{|c|c|c|c|}
\hline Age-Group(Year) & Male & Female & Total \\
\hline $0-1$ & 2 & 5 & $7(1.01 \%)$ \\
\hline $1-4$ & 14 & 20 & $34(4.94 \%)$ \\
\hline $5-9$ & 43 & 31 & $74(10.76 \%)$ \\
\hline
\end{tabular}




\begin{tabular}{|c|c|c|c|}
\hline $10-14$ & 38 & 26 & $64(9.30 \%)$ \\
\hline $15-30$ & 193 & 98 & $291(42.30 \%)$ \\
\hline $31-45$ & 85 & 36 & $121(17.59 \%)$ \\
\hline $46-60$ & 44 & 20 & $64(9.30 \%)$ \\
\hline$>60$ & 23 & 10 & $33(4.80 \%)$ \\
\hline Total & $442(64.24 \%)$ & $246(35.76 \%)$ & $688(100 \%)$ \\
\hline
\end{tabular}

From above table, $442(64.24 \%)$ cases of male and $246(35.76 \%)$ cases of female were found positive for malaria of total cases presenting with fever. Maximum numbers of positive malarial infection were found in $15-30(42.30 \%)$ and $31-45(17.59 \%)$ age groups.

Table 4: Season wise prevalence rate of malaria

\begin{tabular}{|l|c|c|}
\hline Winter(November-February) & $93(0.7 \%)$ & 13158 \\
\hline Summer(March-June) & $120(1.18 \%)$ & 10147 \\
\hline Monsoon(July-October) & $475(2.58 \%)$ & 18355 \\
\hline Total & $688(1.65 \%)$ & 41660 \\
\hline
\end{tabular}

The maximum cases of malaria were reported from July to November, with a peak in September (Table 4 and Graph 1) due to climate is favourable for vector breeding.

\section{Discussion}

Most of the areas in western India fall in an unstable malaria zone in the country. Malaria, a seasonal disease has a cyclic trend of low and high incidences and is often influenced by environmental factors and poor surveillance..$^{7-9}$ Good rainfall, relative humidity of $60 \%$ and temperature between 20 and $30^{\circ} \mathrm{C}$ favour the spread of malaria. ${ }^{10}$ In India, about $65-70 \%$, $25-30 \%, 4-8 \%$ and $1 \%$ of malarial infections are due to P. vivax, P. falciparum, mixed infection and $P$. Malariae respectively ${ }^{11}$. In present study, $77.80 \%$ was due to P. vivax, $21.90 \%$ due to P. falciparum and $0.30 \%$ due to mixed infection. From Table 5, this study was very much comparable to different studies which were done in different places of Gujarat and western region of India due to similar environmental condition, modernisation, and urbanisation. Our observation was also convinced by studies done by Upadhyayula et al., ${ }^{25}$ Chery et al. ${ }^{26}$ Rashmi Sharma et $\mathrm{al}^{27}$ and Sharma et al. ${ }^{28}$ The predominance of $P$. vivax cases can be due to different load of parasite, difference in density and capability of vector, host parasite relationship means new cases of P. vivax from migration of people to this area. $^{24}$

Table 5: Comparison of Various Studies from Various Places

\begin{tabular}{|c|c|c|c|c|}
\hline Study & Year & Place & P.vivax & P.falciparum \\
\hline Sidhu et al. ${ }^{12}$ & 1991 & Kerala & $40.60 \%$ & $50 \%$ \\
\hline Anand et al. ${ }^{13}$ & 1999 & North India & ,- & $85.36 \%$ \\
\hline Muddaiah et al., ${ }^{14}$ & 2006 & Karnataka & $52.40 \%$ & $33.75 \%$ \\
\hline B. Prajapati et al., 15 & 2006 & $\begin{array}{l}\text { Mahesana, North } \\
\text { Gujarat }\end{array}$ & $92 \%$ & $8 \%$ \\
\hline Amit et al., ${ }^{16}$ & 2012 & Rajkot, Gujarat & $34 \%$ & $66 \%$ \\
\hline $\begin{array}{l}\text { Kevadiya SM et } \\
\text { al., }{ }^{17}\end{array}$ & 2012 & Surat, Gujarat & $60.68 \%$ & $38.32 \%$ \\
\hline Balpande et al. ${ }^{18}$ & 2014 & Madhya Pradesh & $95.10 \%$ & $4.80 \%$ \\
\hline Sweta et al., ${ }^{19}$ & 2015 & Ahmedabad, Gujarat & $95.83 \%$ & $4.13 \%$ \\
\hline $\begin{array}{l}\text { Gurjeet Singh et } \\
\text { al., }{ }^{20}\end{array}$ & 2015 & Mumbai & $54.76 \%$ & $17.80 \%$ \\
\hline Ruby Naz et al., ${ }^{21}$ & 2016 & Haryana & $73.90 \%$ & $24.60 \%$ \\
\hline $\begin{array}{l}\text { Sanjeev kumar et } \\
\text { al., } 22\end{array}$ & 2016 & Udaipur & $69 \%$ & $31 \%$ \\
\hline Panchal PD et al.,23 & 2016 & $\begin{array}{l}\text { Himmatnagar, North } \\
\text { Gujarat }\end{array}$ & $64 \%$ & $35 \%$ \\
\hline $\begin{array}{l}\text { H. K. Namera et } \\
\text { al. }{ }^{24}\end{array}$ & 2017 & Rajkot, Gujarat & $78.60 \%$ & $21.40 \%$ \\
\hline Present Study & 2018 & $\begin{array}{l}\text { Palanpur, North } \\
\text { Gujarat }\end{array}$ & $77.90 \%$ & $21.80 \%$ \\
\hline
\end{tabular}

We found maximum number of Malaria cases i.e. $291(42.30 \%)$ in $15-30$ years of age group comparable to H. K. Namera et al. ${ }^{24}$ study. The reason of higher prevalence in this age group could be due to movement in wider areas possibly endemic, more chances of exposure to mosquito bites and most of carefree behaviour. ${ }^{20} 64.24 \%$ males were affected higher than females comparable to study done by H. K. Namera et 
al., ${ }^{24}$ Kumar et al., ${ }^{29}$ Karlekar et al. ${ }^{30}$ and Pathak et al. ${ }^{31}$ There was male predominance in this study probably due to different in wearing pattern of clothes, movement of males in wider areas, more chances of mosquito bites, some unknown inherent susceptibility or more male patients attend the hospital. ${ }^{20}$ It was observed from the study, that the disease transmission occurred throughout the year but, average to higher number of case were recorded in rainy season i.e. in July to October month and highest cases were reported in September month. ${ }^{24}$ Maximum rainfall was seen during July month and rainfall occurred from July to September month. ${ }^{24}$ According to WHO report, moderate rainfall, instead of high volume, was found to be more favourable for malaria incidence. ${ }^{1}$ The factor of rainfall influences the transmission of malaria by creating the breeding sites and also increases the relative humidity, which is favorable for mosquito, parasite development and disease transmission. ${ }^{25}$ On the other hand, abundant rainfall wash out the breeding sources which may lead to decrease in the mosquito population and reflects on decrease in number of malaria incidences..$^{25}$ In other than rainy season, malaria cases were also occurred. This is due to the availability of vector habitation, existence of permanent water bodies, such as slow-flowing rivers and lakes which provide suitable breeding sites for malaria vectors. ${ }^{24}$

\section{Conclusion}

From our study we concluded that there was high prevalence of P. vivax than P. Falciparum infection, higher in monsoon in comparison to other seasons. The present study reveals that rainfall and ambient temperature plays a key role in the malaria. These finding are alarming for us as despite of various programmes for prevention and control of malaria the incidence of malaria still remains major burden to our country. So morbidity and mortality of malaria must be reduced by strengthening Malaria Surveillance, risk factor assessment during pre and postmonsoon period. Premonsoon preventive actions need strengthening and strict monitoring of all these actions.

\section{References}

1. HO. World malaria report 2013. Geneva: World Health Organization; 2013. Available from: www.who.int/iris/bitstream/10665/97008/1/978924156 4694_eng.pdf, accessed on march 11, 2014.

2. Parasitology (Protozoology and Helminthology) by K.D. Chaterjee, $13^{\text {th }}$ edition, Feb 2011, CBS Publishers and Distributors pvt. ltd.

3. Malaria-Fact sheet, WHO. Updated April 2016. Available from: http://www.who.int/mediacentre/factsheets/fs094/en/.

4. Pemola N, Jauhari RK. Climatic Variables and Malaria Incidence in Dehradun, Uttaranchal, India. J Vect Borne Dis 2006;43(1):21-8.

5. Snow RW, Guerra CA, Noor AM, Myint HY, Hay SI. The global distribution of clinical episodes of
Plasmodium falciparum malaria. Nature 2005;43(4):214-7.

6. Malaria situation. National Vector Borne Disease control Programme. Available at http://nvbdcp.gov.in/ Doc/mal_situation_Jan2015.

7. Bouma MJ, van der Kaay HJ. Epidemic malaria in India and the El Nino Southern Oscillation. Lancet 1994;344:1638-39.

8. Mathur KK, Harpalani G, Kalra NL, Murthy GGK, Narasimham MVVL. Epidemic of Malaria in Barmer District (Thar Desert) of Rajasthan during 1990. Ind J Malariol 1992;29: 1-10.

9. Sharma RC, Gautam AS. Studies on outbreak of malaria in Muliad Village of Kheda District, Gujarat. Ind J Malariol 1990;27:157-62.

10. Bonnlander H, Rossignol AM, Rossignol PA. Malaria in Central Haiti: a hospital based retrospective study, 1982-1986 and 1988-1991. Bull Pan Amer Hlth Org 1994;28(1):9-16.

11. Park K. Text book of preventive and social medicine. XVII edition, November 2015;193.

12. Sidhu P.S, Ngsc. A retrospective study on malaria cases admitted to the University hospital, Kerala Lumpur, Med J Malaysia 1991;46:177-82.

13. Anand K., Kant S. and Kumar G Clinical case definition of malaria at a secondary level hospital in northern India. Southeast Asian J Trop Med Public Health 1999;30:243-5.

14. Madhu Muddaiah and Prakash P.S., A study of clinical profile of malaria in a tertiary referral centre in South Canara, J Vector Borne Dis 2006;43:29-33.

15. B Prajapati, A Patel, M Patel. Study of Hospital Based Malaria Cases In Mehsana District Of North Gujarat. Internet J Third World Med 2006;5(1).

16. Amit H. Agravat, Gauravi A. Dhruva, Khyati Babaria, Kalpesh Rathod Clinico-Hematological pattern of Malaria in Rajkot city, Gujrat, India. Int J Biomed $A d v$ Res 2012;03:11.

17. Kevadiya SM, Patel MM, Modi J, Gamit B, Patel PR, Padsala S. Characteristic and trends of malaria in Surat district of Gujarat: a hospital based study. Int J Res Med Sci 2014;2:151-3.

18. Balpande L, Gupta SK, Agarwal SS Epidemiological trends of malaria cases in rural health and training centre of Madhya Pradesh. Natl J Community Med 2014;5(2):227-9.

19. Sweta M Murawala, Vyoma Chudasama, Mahendra Vegad Prevalence of mosquito-borne Plasmodium infection in patients attending fever clinic in a tertiary care teaching hospital, western India. Int J Med Sci Public Health 2015;4:11.

20. Singh G, Urhekar AD, Maheshwari U, Sharma S, Raksha (2015) Prevalence of Malaria in a Tertiary Care Hospital in Navi Mumbai, India. J Bacteriol Parasitol 6: 221.

21. Ruby Naz, Mohammad Khalid Farooqui, Ruchi Girotra and A. K. Malik. 2016. Pattern of Malaria Infection at Tertiary Care Hospital of Haryana-A Hospital Based Study. Int J Curr Microbiol App Sci 5(2):330-37.

22. Sanjeev Kumar and Naseer Khan. 2016. Prevalence and Detection of Malaria at a Tertiary Care Hospital in Southern Rajasthan, India. Int J Curr Microbiol App Sci 5(8):663-68. 
23. Panchal PD, Trivedi MB, Shethwala N, Khatri HS. A study of prevalence and seasonal trends of different malarial species in district hospital. Int J Res Med Sci 2016;4:4155-7.

24. H K Namera, V S Gohil, U V Patel, Z R Matariya Epidemiological Determinants for Malaria in Rajkot Municipal Corporation, Gujarat Healthline J 2017;8(1):49-54

25. Upadhyayula SM, Mutheneni SR, Chenna S, Parasaram V, Kadiri MR (2015) Climate Drivers on Malaria Transmission in Arunachal Pradesh, India. PLoS ONE 10(3): e0119514. doi:10.1371/journal.pone.0119514.

26. Laura Chery, Jenifer N. Maki, Anjali Mascarenhas, Jayashri T. Walke, Pooja Gawas, Anvily Almeida et al. Demographic and clinical profiles of Plasmodium falciparum and Plasmodium vivax patients at a tertiary care centre in southmwestern India. Malar J 2016;15:569.

27. Rashmi Sharma. Epidemiological Investigation of Malaria Outbreak in Village Santej, District Gandhinagar (Gujarat). Ind J Prev Soc Med 2006;37(3\&4)

28. Sharma R, Ahmed S, Gupta S. Comparative evaluation of seasonal fevers in last 2 years at a tertiary care hospital in North India. Int J Curr Microbiol App Sci 2014;3(7):631-4.

29. Kumar A, Valecha N, Jain T, Dash AP. Burden of malaria in India: retrospective and prospective view. Am J Trop Med Hyg 2007;77(6 Suppl):69-78.

30. Karlekar SR, Deshpande MM, Andrew RJ. Prevalence of Asymptomatic Plasmodium vivax and Plasmodium falciparum Infections in Tribal Population of a Village in Gadchiroli District of Maharashtra State, India. An Int J 2012;4(1):42-4.

31. Pathak S, Rege M, Gogtay NJ, Aigal U, Sharma SK, et al. (2012) Age-Dependent Sex Bias in Clinical Malarial Disease in Hypoendemic Regions. PLoS ONE 7(4):e35592. doi:10.1371/journal. pone.0035592 